\title{
Professional Learning Opportunities in a Practice-Based Teacher Education Programme about the Concept of Function
}

\author{
Alessandro Jacques Ribeiro ${ }^{1}$ \\ João Pedro da Ponte ${ }^{2}(\mathbb{D}$ \\ ${ }^{1}$ Universidade Federal do ABC (UFABC), Programa de Pós-Graduação em Ensino, História, Filosofia \\ das Ciências e Matemática, Santo André/SP, Brazil \\ ${ }^{2}$ Universidade de Lisboa, Instituto de Educação da Lisboa (IEUL), Lisboa, Estremadura, Portugal
}

Received for publication on 15 Jan. 2019. Accepted, after revision, on 20 Mar. 2019.

\begin{abstract}
This article aims to identify professional learning opportunities (PLO) experienced by mathematics teachers during an in-service course regarding their mathematical and didactical knowledge on the concept of function. The conceptual framework distinguishes between mathematical and didactical knowledge and characterises teacher learning and professional learning tasks. The research methodology is qualitative, using participant observation with audio and video recording and document collection. The results show that the professional learning tasks proposed enabled to identify PLO regarding mathematical knowledge of function, involving different ways of representing this concept by means of numeric tables and algebraic notation. Regarding didactical knowledge, there were also PLO supporting reflection about difficulties that the students find with the concept of function and about teaching resources and strategies to overcome those difficulties.
\end{abstract}

Keywords: Teacher education. Mathematical knowledge. Didactical knowledge. Professional learning opportunities. Algebra Teaching.

\section{Oportunidades de Aprendizagem Profissional em um Programa de Formação de Professores Baseado em Práticas sobre o Conceito de Função}

\section{RESUMO}

Este artigo tem como objetivo identificar oportunidades de aprendizagem profissional (OAP) vivenciadas por professores de matemática durante um curso de capacitação quanto ao seu conhecimento matemático e didático sobre o conceito de função. O quadro conceptual distingue entre o conhecimento matemático e o didático e caracteriza a aprendizagem do professor e as tarefas de aprendizagem profissional. A metodologia de pesquisa é qualitativa, utilizando observação participante com gravação de áudio e vídeo e coleta de documentos. Os resultados mostram que as tarefas de aprendizagem profissional propostas permitiram identificar a OAP em relação ao conhecimento matemático da função, envolvendo diferentes formas de representar esse conceito por meio de tabelas numéricas e notação algébrica. Quanto ao conhecimento didático,

Corresponding author: Alessandro Jacques Ribeiro.

Email: alessandro.ribeiro@ufabc.edu.br 
houve também a OAP apoiando a reflexão sobre as dificuldades que os estudantes encontram com o conceito de função e sobre o ensino de recursos e estratégias para superar essas dificuldades. Palavras-chave: Formação de professores. Conhecimento matemático. Conhecimento didático. Oportunidades de aprendizagem profissional. Ensino de Álgebra.

\section{INTRODUCTION}

Many studies have documented students' failure in algebra (Bush \& Karp, 2013; Cyrino \& Oliveira, 2011; Kaput, 2008; Matos \& Ponte, 2009; Stephens \& Ribeiro, 2012) and the difficulties faced by teachers when teaching it (Barbosa \& Ribeiro, 2013; Doerr, 2004; Hung \& Kulm, 2012; Li, 2007; Chazan, Yerushalmy \& Leikin, 2008; McCrory et al., 2012; Pazuch \& Ribeiro, 2017; Ribeiro, 2012; Wasserman, 2015). In particular, regarding the teaching and learning of functions, a key algebraic concept (McCrory et al., 2012), results from earlier research show difficulties from students to learning and from teachers to teaching this content (Even, 1993; Llinares, 2000; Webber, Tallman \& Middleton, 2015; Hatsaru \& Erbas, 2017; Panaoura et al., 2017). Therefore, it is important to study how teacher education programs can prepare teachers to address these difficulties in their teaching practice.

Mathematics teacher education has a long record of inefficiency both at pre-service (Lampert \& Ball, 1998) and in-service level (Smith, 2001). Many factors may contribute for this inefficiency, including the prevalence of transmission pedagogies (Lampert \& Ball, 1998; Lesne, 1984; Loucks-Horsley, Hewson, Love \& Stiles, 1998), the weak connection with teaching practice (Smith, 2001), and the lack of attention to how teachers learn (Bransford, Brown \& Cocking, 2000). In recent years, teaching practice is assuming a central role in the teacher education processes (Ball \& Cohen, 1999; Ponte

\& Chapmann, 2008), by using representations, decomposition, and approximations of practice (Grossman et al., 2009). Of particular importance are teachers' experiences in spaces of collective work and discussion that encourage reflection on their knowledge and sharing of their experiences of classroom practice. Tasks that promote teachers' professional learning opportunities (Ball \& Cohen, 1999; Lampert, 2010; Silver et al., 2007; Smith, 2001; Swan, 2007) may be important levers to promote such experiences.

In our research, we take as professional learning opportunities (PLO) collective moments in which practicing teachers work and discuss mathematical and didactical situations in order to amplify their professional knowledge for teaching. In this perspective, this article aims to explore the potential of professional learning opportunities provided to mathematics teachers concerning their mathematical and didactical knowledge of the concept of function.

\section{MATHEMATICS TEACHER'S PROFESSIONAL LEARNING}

A key perspective in teacher education is that teachers' professional learning must be strongly anchored in classroom practice (Ball \& Cohen, 1999; Lampert, 2010; Smith, 
2001; Webster-Wright, 2009). Giving central attention to classroom practice involves taking into account the teacher, the school (context), and the learning activities and/or tasks. When considering the teachers, the school and their tasks/activities, Ball \& Cohen (1999) and White, Jaworski, Agudelo-Valderrama \& Gooya (2013) underline that their professional learning occurs as a collective process. These authors argue about creating opportunities for teachers to learn from each other, thus breaking the traditional isolation of their work, expanding their opportunities to learn collectively. Also in this perspective, Bruce et al. (2010) indicate that the classroom environment is fundamental for building opportunities for teachers' professional learning so that they become involved with the "use of interactive cycles of [classroom] planning, development and reflection" (p.1599).

Key elements of those professional learning opportunities (PLO), are professional learning tasks (PLT), that is, "tasks that involve teachers in the work of teaching, can be developed in order to find a specific goal for teachers' learning and takes into account the previous knowledge and experience that teachers bring to their activity" (Ball \& Cohen, 1999, p.27). Thus, we are using professional learning tasks as part of the process of mathematical and didactical teacher education, including teachers' experience in spaces of collective work and discussion (Cristovão \& Fiorentini, 2018). Such experiences support teachers' reflection on their knowledge and sharing of experiences of classroom practice, mediated by tasks informed by mathematics education research (Ball \& Cohen, 1999, Ponte, 2012b; Silver et al., 2007; Smith, 2001; Swan, 2007). As Watson and Mason (2007) point out, unlike the significant production concerning the role of tasks in student learning, there is a considerable gap in the literature about studies that analyse the role of tasks in teacher learning.

\section{TEACHER'S MATHEMATICAL AND DIDACTICAL KNOWLEDGE AND THE CONCEPT OF FUNCTION}

To characterise teaching professional knowledge, Shulman (1986) introduced the concept of "Pedagogical Content Knowledge" (PCK) as a special combination of pedagogy and subject-matter knowledge. This concept has been an important reference for many researchers from different areas of knowledge, who deepened and/or adapted it in their investigations. A much used perspective in mathematics teacher education is the "Mathematical Knowledge for Teaching” (MKT) (Ball et al., 2008). This theoretical model presents six different domains, including the Common Content Knowledge (CCK), the Specialized Content Knowledge (SCK), the Knowledge of Content and Students $(S C K)$ and the Knowledge of Content and Teaching (KCT). The authors give as examples of CCK, to recognize a wrong answer, of SCK, to rapidly identify the nature of an error, especially of a non-familiar one, of KCS, to know the common errors and learn why many students make mistakes, and of KCT, to select a teaching approach that is efficient to overcome certain difficulties and/or explore certain aspects of a concept.

In a different perspective, Ponte $(1994,1999)$ considers that a core domain of professional knowledge is didactical knowledge. In his view, this knowledge is strongly 
oriented toward action and mobilises elements of four deeply interrelated domains: school mathematics, curriculum, students' learning, and instructional processes and materials. In his view, this knowledge "is closely related with various aspects of personal and informal knowledge teachers have of everyday life, such as the knowledge of the context (of the school, community, society) and the knowledge they have of themselves" (p.3).

We take the concepts of common content knowledge (CCK) and specialised content knowledge (SCK) as the knowledge that the teacher demonstrates and mobilises while developing professional learning tasks. Also, we take Ponte's concepts (1999) in order to understand what mathematical and didactical knowledge teachers mobilise and develop when facing professional learning tasks.

With regard to teachers' mathematical and didactical knowledge of the concept of function, we assume that every secondary student should have the ability to define function and to be able to recognise examples of functions and non-functions. For this, it is important that teachers hold common and specialised knowledge regarding the definition of function (Cooney et al., 2011) as well as the ability to provide key examples of functions, such as linear and quadratic functions. Stelle et al. (2013) argue that a relevant aspect of SCK of functions needed by teachers is the ability to mobilize and use multiple representations of functions (symbolic expressions, tables, graphs, mappings, verbal expressions, and contextual situations) and to make connections among them (Lesh et al. 1987). Many secondary mathematics teachers privilege the symbolic form of functions, leaving aside the work with graphs and other contexts of functions (Stelle et al., 2013). This approach undermines students' ability to understand functions, leastwise, in two important dimensions of knowledge of functions in the secondary mathematics teaching: to mobilise and coordinate different forms of representation functions (Lesh et al., 1997) and to recognise and to distinguish algebraic representations of proportional and non-proportional functions.

\section{THE PRACTICE-BASED TEACHER EDUCATION PROGRAMME}

The course "The teaching of algebra for basic education" was part of a process of in-service education of teachers in the state of São Paulo, Brazil,1 and unfolded during nine months (March to December 2016), with priority given to developing theoretical studies (as mathematical and didactical knowledge, see Ponte, 1999) and their relationship with classroom practice. It included analyses and discussions of different activities involving algebra and its teaching, with special attention given to algebraic structures and their connections with school algebra (McCrory et al., 2012).

\footnotetext{
1 The course is part of a broader research project, "Mathematical Knowledge for Teaching Algebra: an approach based on conceptual profiles", conducted at Federal University of ABC (UFABC), and funded by Capes (Commission for the Improvement of Higher Education Staff) within "Programa Observatório da Educação" (OBEDUC) (Project 1600/2012).
} 
The team of educators who organised and developed the course was composed of of university instructors and students of the graduate degree programme in mathematics education and of the undergraduate teaching degree in mathematics.2 The team was divided into subgroups, each consisting of at least two university instructors, two graduate students and one undergraduate student. Each subgroup was responsible for different mathematical themes concerning algebra and its teaching. A university instructor and a graduate student conducted the meetings. Every week the subgroups met to discuss and organise the meetings, and every month the whole team gathered to reflect on the course progress, results and next actions.

For the participating teachers, the course aimed (i) to discuss different meanings of algebraic concepts that are mobilised in the processes of teaching and learning basic school mathematics and (ii) to know and understand the role of mathematical tasks that involve different meanings of algebraic concepts. The course was presented in 180 working hours divided into two modules of 90 hours. There were thirty-one face-to-face meetings and nine distance-learning activities, each with a duration of 4 hours and 30 minutes. Over the nine months, two main topics were considered: (1) sets of natural and integer numbers, notions of ring and polynomial rings, set and field of rational numbers; and (2) study of functions and equations and their connections with basic education. Figure 1 presents the structure of the course, with emphasis on the moment in which the data considered in this article were produced.

The face-to-face meetings took place at the premises of the university, always in a collaborative work environment. At this initial stage, the teachers were invited to share their previous knowledge and experiences on the topic. The theoreticalmethodological principles of the meetings were the dialogue, reflection, thematisation of practice (using records on/from mathematics teaching at elementary school (Smith, 2001). The meetings were always mediated by Professional Learning Tasks (PLT), prepared by the teacher education team (Ball \& Cohen, 1999). Table 1 shows an overview of the meetings developed.

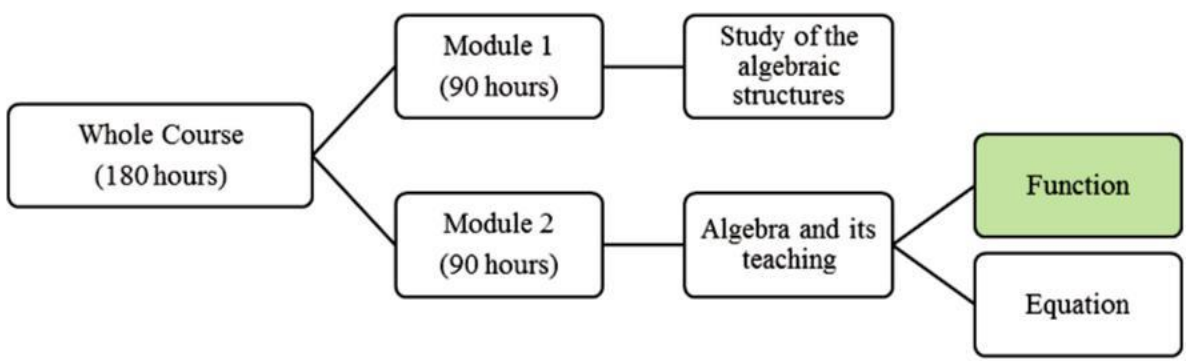

Figure 1. Organisational design of the course.

\footnotetext{
2 Members of the research group "FORMATE - Mathematics Training for Teaching", which investigates the professional development of the mathematics teacher and the teaching of algebra.
} 
Table 1

Activities conducted in the course on the topic of functions.

\begin{tabular}{|c|c|}
\hline Meeting $\mathbf{n}$. & Activity conducted \\
\hline \multirow{2}{*}{$\begin{array}{c}1 \\
(02 / 09 / 2016)\end{array}$} & Exploitation of mathematical situations on the concept of function \\
\hline & Theoretical Studies: "Algebra, its teaching and learning" \\
\hline $\begin{array}{c}2 \\
\text { (distance learning) } \\
(09 / 09 / 2016)\end{array}$ & $\begin{array}{l}\text { Theoretical Studies: "Algebra and its teaching, what curricular documents, examinations } \\
\text { and research point to" }\end{array}$ \\
\hline $\begin{array}{c}3 \\
(16 / 09 / 2016)\end{array}$ & Theoretical Studies: "Epistemology of the concepts of Equation and Function" \\
\hline \multirow{4}{*}{$\begin{array}{c}4 \\
(23 / 09 / 2016)\end{array}$} & $\begin{array}{l}\text { Theoretical Studies: "Learning difficulties in Algebra, the concepts of Equation and } \\
\text { Function" }\end{array}$ \\
\hline & Carrying out the Professional Learning Task 1 - PLT1 \\
\hline & Carrying out the Professional Learning Task 2 - PLT2 \\
\hline & "Studying functions from a mathematical and didactical point of view" \\
\hline \multirow{3}{*}{$\begin{array}{c}5 \\
(30 / 09 / 2016)\end{array}$} & $\begin{array}{l}\text { Theoretical Studies: "Mathematical Activities about the concepts of equation and } \\
\text { function, analysing the results of research in Mathematics Education" }\end{array}$ \\
\hline & Carrying out the Professional Learning Task 3 - PLT3 \\
\hline & Carrying out the Professional Learning Task 4 - PLT4 \\
\hline \multirow{2}{*}{$\begin{array}{c}6 \\
(07 / 10 / 2016)\end{array}$} & Carrying out the Professional Learning Task 5 - PLT5 \\
\hline & $\begin{array}{l}\text { Collective discussion of lesson plans about the concept of function and choice of } \\
\text { plans to be carried out in schools }\end{array}$ \\
\hline \multicolumn{2}{|c|}{$\begin{array}{l}7 \text { Carrying out the Professional Learning Task 6 - PLT6 (two classes on the concept of } \\
(04 / 11 / 2016) \text { function for Elementary School) }\end{array}$} \\
\hline $\begin{array}{c}8 \\
(16 / 12 / 2016) \text { func }\end{array}$ & $\begin{array}{l}\text { Carrying out the Professional Learning Task } 6 \text { - PLT6 (two classes on the concept of } \\
\text { ion for High School) }\end{array}$ \\
\hline
\end{tabular}

All professional learning tasks had a common structure that included (i) mathematical tasks, often similar to those that could be used with students, aiming to identify and develop teachers' mathematical knowledge about the concept of function, which were followed by (ii) didactical questions, aiming to identify and develop teachers' didactical knowledge regarding students and the concept of function, as well as their knowledge about the teaching of this topic.

In this article, we analyse PLT2 (Appendix I). This task aimed to lead participant teachers to reflect and identify their knowledge about the different representations of functions (numerical/tabular, algebraic, geometrical), according to Lesh et al. (1987); what kinds of mathematical knowledge about function (Stelle et al., 2013) the participant teachers demonstrate; and, finally, if the teachers identified the situations in which functions were proportional or not (Lamon, 2012). 
The data analysed in this work were produced at the fourth meeting, and the methods we used in such analysis are discussed in the next section. This meeting began with the discussion led by two teachers educators of Chapter 4 by Ribeiro \& Cury (2015), with emphasis on the difficulties students found in the learning of equations and functions. It followed the work on PLT2 with the analysis of the mathematical and didactical situation regarding the concept of function, drawn from research in mathematics education.

\section{RESEARCH METHODOLOGY}

Participants: The participants of our study were teachers who teach mathematics in Brazilian schools in grades 6 to 12 (just three of them does not teach yet). The group was formed by 11 male and 5 female teachers, with an average age of 33 years. There were no special criteria to select participants, once all of them were attending the programme. Most participating teachers (PT) had a degree in mathematics. Along the meetings, two university instructors also teamed up, as teacher educators. They have doctorate degrees in mathematics education. One of them with 10 years of experience in mathematics teacher education and research in mathematics education. The other has had a doctorate for two years, being at the moment doing a research practicum with the principal educator/researcher.

Data sources and analysis method: This study follows a qualitative research approach (Bogdan \& Biklen, 1994; Esteban, 2010), under a theoretical interpretative focus (Crotty, 1998). The participating teachers worked in groups of 3 to 5 members in PLT2. Data was collected by means of video and audio recordings, within each group, as well as through written protocols resulting from the development of the task. The recordings were transcribed in full, in order to identify episodes in which the PLO concerning mathematical and didactical knowledge of the concept of function were relevant.

Data analysis is organised in two parts, in situations encompassing discussions focused on the mathematical and didactical knowledge of the concept of function. Although in PLT2 there were items addressing "knowledge of function and of the students" and "knowledge of function and the teaching", the participating teachers eventually worked with the items together, so our analysis of the discussions focuses on these two aspects in an articulated manner. We present excerpts of PLT2 with the responses of the PT. To make explicit the evidence considered in the interpretative process of our analysis, we present (a) the protocols of solutions produced by PT and (b) the transcripts of the dialogues within each group considered in our analysis, namely G1, G2 and G3.3

${ }_{3}$ G1: PT1, PT2, PT3, PT4; G2: PT11, PT12, PT13; G3: PT5, PT6, PT7. The groups G1, G2 and G3 were selected among the 5 participating groups, because they are a heterogeneous group in terms of (i) the time of professional experience, with teachers at the start of their careers and others with extensive experience; (ii) the time of completion of initial training, with newly qualified teachers and others with over 10 years of undergraduate; (iii) the level of education in which they acted, with teachers who work both in the final years of elementary education (middle school) and in high school; (iv) the type of schools in which they worked, comprising teachers who teach in public schools and others teaching in private schools. 
We organise the first part (focusing on mathematical knowledge) taking into account each item that comprised PLT2, i.e., we analyse each item according to the work of the three groups taken together. Yet, in the second part (centred on didactical knowledge), the analysis was performed per group, considering, at the same time, the three items of PLT2. This organisation is because the PT themselves, on several occasions, answered and discussed together the different items of this second part. For example, while the PT thought about students' difficulties (item $\boldsymbol{e}$ ), they started considering the possibilities of different teaching resources for teaching function (item $f$ ).

\section{FINDINGS}

\section{Mathematical Knowledge of Function}

The first part of the PLT2 (see Appendix I) presented three numeric tables (items $\boldsymbol{a}, \boldsymbol{b}, \boldsymbol{c})$ representing three different polynomial functions. The participants were requested to find some values that had been omitted in these tables, culminating with the request to determine the general rule, the symbolic representation of the function (questions a.1, a.2, a.3, a.4, a.5, a.6; b.1, b.2, b.3; c.1, c.2, c.3).

Item a). In the protocol shown in Figure 2, we observed G1's response, which was recorded without any discussion about how the group came to this response.

5) escreva, com suas palavras, a regra que leva cada $x$ no y correspondente.

$$
\text { soma-se cince unidades at } x \cdot(y=x+5)
$$

(5) write, with your own words, the rule that yields each $x$ to the corresponding $y$.

We sum five units to $x(y=x+5)$

Figure 2. G1 protocol, question a.5, PLT2.

Although they were organised to work in a group, we observed at the outset that the PT of G1 began PLT2 individually. Apparently, items $\boldsymbol{a}, \boldsymbol{b}, \boldsymbol{c}$ of PLT2 do not invite them to work as a team. Our interpretation leads us to infer that, once they had enough mathematical knowledge to resolve the situations proposed, they did not feel the need for discussion, dialogue and exchange of ideas. At this moment, individual work prevailed. The group discussion begins with the completion of item $\boldsymbol{d}$, when a "didactical analysis" of the tasks that had been proposed is requested. This and other evidence that emerged during the process of analysis drew our attention to the fact that the PT of this group felt little comfortable to conduct, on their own, a didactical analysis of the tasks. 
In group G2, we observed, from the start, that the PT, from the table and data provided, sought to identify, by discussion, the function rule, so that they could complete what was being requested of them in questions $\boldsymbol{a} .2$ and $\boldsymbol{a} .3$ of PLT2:

PT12: What is that? " $x+5$ ”, seems?... [PP13 interrupts and speaks]

PT13: So, let's see "from 1 it went to 6"... from "2 it went to 7 "... from "3 it went to 8 "... [...] If $i$ did $x \ldots$ " " $5 x+1$ equals 6 "... " $5 x+2$ is 7 " [see that PT13 seems to consider as if $x$ were always equal 1]... It could be " $5 x$ " actually... I believe it is " $5 x$ ".

PT12: Only " $5 x$ ”? Without the term " $b$ ", you say?

PT13: It would be " $5 x+1$ ". Take a look here! How much it would be if $x$ were 0 ? Let us see: "It would take this, look..." 'f of $x$ gives $5 x \ldots$ No, not 5x'.

PT12: Would it not be " $x+5$ "?

PT13: “ $x+5$ !"

PT12: “ $x+5$ ”, isn't it?

PT13: “ $x+5$ ”.

It is interesting to note, in the transcript above, that, although PT12, from the very start, had already identified the function rule as being " $x+5$ ", he lets PT13 test the values and reach, even though incorrectly, the law " $5 x+1$ ”. PT12 does not impose his discourse, his response. He lets PT13 notice that the mathematical expression identified was incorrect and so, in a negotiation, convinces the colleague that the correct expression would be " $x+5$ ", showing, with numerical values, it was just that. We observed, in PT12's attitudes, a type of positioning that you want to find in a teacher, i.e., he leads a (mathematical) discussion through negotiation, giving voice to the others (in a classroom, to the students), seeking to consider and evaluate the responses of the others without imposing his position and/or his response, even if that is the correct or the most appropriate one.

In the case of G3, we observed that teachers do not have difficulties in finding the values requested in questions $\boldsymbol{a} .1, \boldsymbol{a} .2, \boldsymbol{a} .3$ and $\boldsymbol{a . 4}$. However, when they get to item $\boldsymbol{a . 5}$, PT7 shows not to be familiar with what is being requested. Let us see:

PT7: Write with your own words... write with my words [amazed]? [...]

PT5: [Continuing] [...] The rule which leads each $x$ to its correspondent $y$ [...] $f(x)=x+5$

PT6: Yes $[\ldots]$

PT7: But how would that be 'with my own words'? [...]

PT5: The value of $y$ will be the value of $x$, added of $5 . .$.

PT6: Added, incremented...

PT5: No, only units, because it is not, what it is, right? [...] 
In our interpretation, PT7, and possibly other members of the group, does not have the habit of considering, in their mathematics lessons, the verbal representations as an important means of expression of mathematical knowledge. When we are working with the concept of function, for example, it is of fundamental importance to consider the verbal representations, also, because many phenomena that are modelled by means of functions are presented in dayto-day, natural language and not in symbolic mathematical language. Thus, some G3 teachers seem to have a gap in mathematical knowledge about functions with respect to the use of different representations of mathematical concepts.

In general, we realised that none of the groups bothered to indicate the domain-set of that function. No group has expressed anything about the fact the PLT includes, purposely, functions of type $f(x)=a x+b$ (with $a$ and $b$ different from 0 ) and type $f(x)=a x$ (with $a$ different from 0 ), in set $Z$ (the set of whole numbers).

Item b). Turning to item b, groups G1 and G3 wrote $Q=3 p$, while group G2 wrote $f(p)=3 p$. As noted earlier, G1 teachers work individually in the resolution of questions $\boldsymbol{b} . \mathbf{1}, \boldsymbol{b} .2$ and $\boldsymbol{b} .3$. Yet, regarding G2, we observed that, again, there seems to be a leader in the conduct of discussions by PT13, even though, again, he starts performing the task by suggesting, incorrectly, a function rule:

PT13: Here it is the same sequence, as well.

PT12: Yes, it is the same style.

PT13: You now have 2 and goes to 6... you have 3... so, here would it be $x_{2}$ ? No, $x_{2}, n o ![\ldots]$

PT12: No, square root [referring to $\left.\mathrm{x}_{2}\right]$, no! [...] 3 became 9 [...] it is $3 x$, see? Because it is " 3 times the value of $x$ " [even though the task uses $p$ and $q$ ].

PT13: Yes, it is 3x.

Also for group G3, there are no discussions in relation to item $\boldsymbol{b}$ of PLT2. It seems that teachers in the group had no difficulty in responding to what was requested, as well as in getting to the function rule. Here, it is noteworthy that: unlike what had been previously presented in question a.5, that members of the group found it difficult to understand, it seems that, here, the fact that the statement requests them to write a rule "with letters and numbers" makes the situation more familiar to teachers (i.e., the use of mathematical symbolic representations). This could have made it easier for them to obtain the answer.

Item c). Finally, when analysing the development of item $\boldsymbol{c}$, we observe that the PT of G1 did not promote discussions to obtain the answers to the items $\boldsymbol{c . 1}, \boldsymbol{c . 2}$ and $\boldsymbol{c . 3}$. This also happened with PT of G2, who indicated their responses in the material received without having discussed or negotiated. Yet, with regard to G3, we observed that PT7 finds it difficult to get the answer of the question $c .2$, what happens later, with the help of the group, since item $\boldsymbol{c}$ was not a linear function (as in items $\boldsymbol{a}$ and $\boldsymbol{b}$ of PLT2). We observed that the G1 group wrote the function rule as $y=3 x+2$, while groups $\mathrm{G} 2$ and 
G3 wrote $f(x)=3 x+2$. All groups calculated the value of y correctly knowing the value of $x(y=38$ when $x=12)$.

Assessing the PLO in relation to mathematical knowledge, we observed that it was possible to teachers, in particular, to G3 members, from the proposed professional learning task to reorganize their knowledge in relation to the different ways to represent a function, because all had the chance to work with numeric-tabular representations and symbolic representation involving algebraic notation. We also noticed that none of the groups questioned the type of function that appeared in the PLT, that is, the linear function with $b$ zero and non-zero term, and they did not bother to indicate the domainset of those functions, an important component of mathematical knowledge when you teach functions in elementary school.

Regarding discussions, we recognise that they occurred more effectively in G3, the group that presented the greatest difficulties to perform the PLT but did not occur in G1, where the teachers felt safe to develop PLT items without major obstacles. In G2, the discussions have played a quite relevant role, since they made possible that one of the teachers recognised his mistakes and another one to exercise the role of facilitator of the mathematical knowledge in question.

\section{DIDACTICAL KNOWLEDGE OF FUNCTION}

As we mentioned before, in this second part of the PLT2, we present the analyses subdivided according to each subgroup, in order to include, in an articulate manner, the knowledge about students and about the teaching concerning the concept of function, since the participating teachers themselves, in certain moments, mixed the discussions of those two aspects.

Group 1. Unlike the first part of the PLT2, we observed that, now, the PT of G1 began to discuss effectively, collectively, the task completion. The discussions between them begin while working on item $\boldsymbol{d}$, but become really interesting when they start considering item $\boldsymbol{e}$, while seeking to raise and identify difficulties that students could present if they were to develop such a task in the classroom:

PT2: What difficulties in solving Task 1 could students present?... in 1? I think none! I think that would be a logicality for them now... 6, 2, 7, 3, 8, 4, 9, 5, 10 [referring to the numbers disposed in the table]... If you have already started at 6, you would just have to check the difference, right? They would do this! At least I would do it! [...]

PT3: What difficulties?

PT2: What do you think? [...]

PT4: What are the difficulties? [...]

PT3: You think none [addressing PT2]... but... I know not, see?

PT4: I think that they would find it difficult! [Laughs!] 


\section{PT3: I agree!}

PT4: To discover this part of the corresponding...

PT3: Exactly!

PT4: That will add every 5... Which increases there... For each $x$ it is increasing 5, I think they would have difficulties, yes!

At this time, we observe that the PT will discuss item $f$ and leave aside the discussion about possible difficulties that students would meet to work with the mathematical situation presented. Although PT3 and PT4, teachers with classroom experience, bring about possible difficulties that students could present during the execution of the task, what prevails is the initial analysis of PT2 (a prospective teacher and without classroom experience) which is presented as a response of the group (Figure 3):

\section{Nấ teriam dificuldades}

(They would have no difficulties)

Figure 3. G1 protocol, item e, PLT2.

It is noteworthy how the lack of experience in/from the classroom practice can create problems an important part of the didactical knowledge, the knowledge about the students. PT2, who has no classroom experience and has not yet completed his undergraduate degree, does not bring to the reflections of the group the fact that students are not accustomed to working from the numeric-tabular representations to obtain the algebraic formulation of the formation law of functions. Although this has been indicated by PT3 and PT4, it seems that their discourse was not strong enough to convince PT2 and lead the group to list and indicate possible difficulties that students may have in the resolution of tasks involving this type of situation.

After that, the group resumes the discussion, but referring now to item $f$, and begin to reflect on teaching resources to accomplish the task proposed:

PT2: So, I can see that that 'thing of $f$ ' [referring to item $f$, the task]...I see this way "look"... "What teaching resources (digital or not) could improve Task 1"... kind of... you could make it more... how could I put it?... [the task would be] a little better to work with. Then I put "the mathematical modelling to represent how the values of $x$ and $y . . . "$ as for the values $x$ and $y \ldots$ [...] I would tell them [the students] to bring some things that depended on each other... [...].

This passage shows that two important elements of the didactical knowledge on the concept of function were placed in discussion, the knowledge of students and the knowledge of the teaching process. An important fact that we observed is the leadership that PT2 takes on G1, despite his inexperience. We saw this both during the discussion about the (possible) difficulties of the students and now when choosing didactical resources 
to accomplish the task. The protocol below (Figure 4) records what PT2 spoke during the discussion and that the group decided that should be registered in the response.

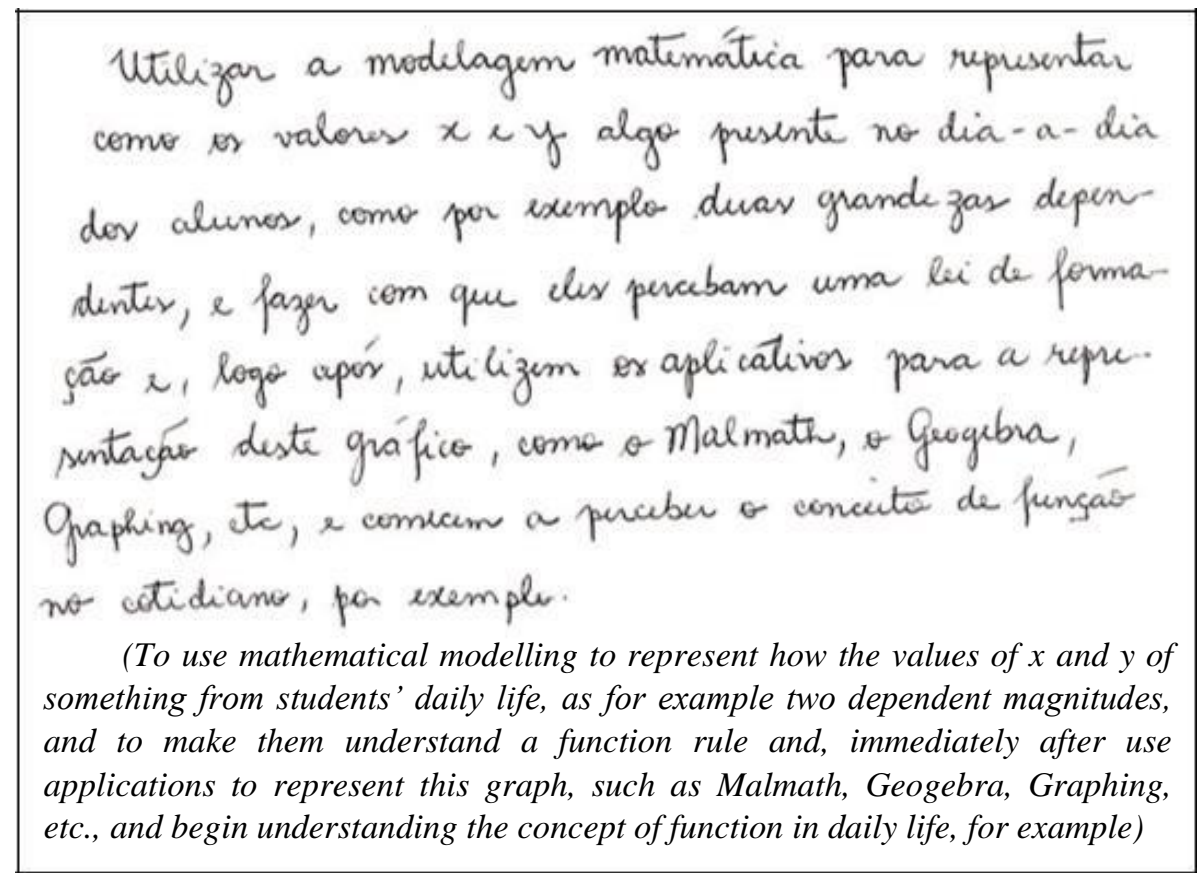

Figure 4. G1 protocol, item $\boldsymbol{f}$, PLT2.

Although PT of G1 uses elements of didactical knowledge, we realise in the group a confusion regarding the concepts of "didactical resource", as in the case of an application like Geogebra, and "teaching approach", as with mathematical modelling. It seems that for teachers, both modelling and Geogebra software are didactical resources, i.e., didactic objects of a similar nature.

We observed that G1 teachers, in particular PT2, have little knowledge of the students' difficulties when they teach functions and, moreover, they do not progress much in discussions about teaching strategies, use of didactical resources, adjustments to the mathematics tasks and adaptations at the level of education that they will work, mathematics learning they want to provide to students. In the case of PT2, this is understandable, given his lack of experience. However, in the case of the other three teachers in the group, it was expected that their classroom practice could contribute to a more critical and thoughtful positioning in the items of PLT2 that included the didactical knowledge of the concept of function, but this did not occur. One of the teachers, PT1, although present, did not participate in the discussions. Thus, we understand that the participating teachers in this group seem to find it more difficult to mobilise elements of didactical knowledge about functions than mobilise mathematical knowledge. 
Group 2. As occurred in G1, from item $\boldsymbol{d}$, the PT of G2, who, until then, had worked in an essentially individual manner, began to work more collectively, although each was seeking individual responses to what had been proposed and, in the end, they came to a unique response from the group (Figure 6).

However, in fact, there is a negotiation process, at least at this stage, because the response adopted by the group is the one that was prepared by PT12. It seems that, at this time, PT12 had already assumed a position of leadership and his responses were embraced by the whole group:

PT13: Yes, you can!

PT12: Look, I wrote something here [what is presented as a response of the group, Figure 5]... I will read, and you will see... [...].

PT13: Great! [Agreeing].

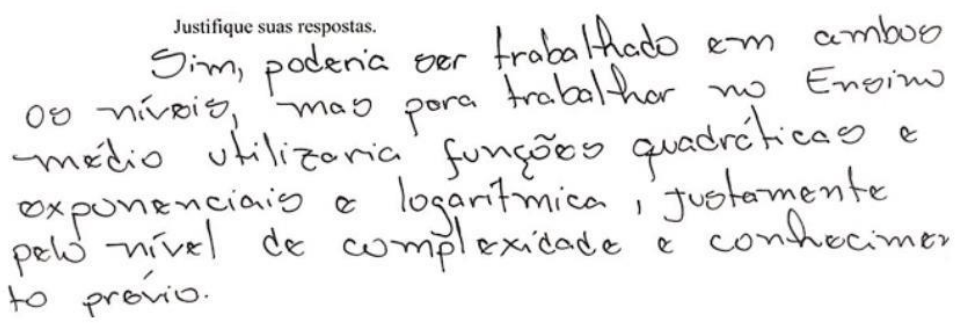

(Justify your responses.

Yes, it could be tackled in both levels, but for the work in secondary school I would use quadratic functions, as well as exponential and logarithmic, because of the level of complexity and previous knowledge)

Figure 5. G2 protocol, item $\boldsymbol{d}$, PLT2.

G2's response seems a "standard response", with a certain level of truism. What the members of the group presented as "adjustments to the task" is, in fact, what appears in the curriculum and in the textbooks about the types of function that must be worked in high school. They are not progressing in other types of adjustments the task could suffer, as, for example, the use of contextualization to let the job more meaningful to students of a certain age.

The teachers go on developing PLT2, but do not progress much in discussions within the group, with few interactions and negotiations between them. PT12 seems to take the lead, but this sometimes goes to PT13. We also noticed that PT11 does not participate in the discussions and has no answers nor questions for what was accomplished and submitted by his group. The G2 teachers discussed and negotiated little the meanings around the didactical knowledge of functions that were required in the second part of the PLT2, unlike what had happened in the first part. 
G2 teachers were not seen to deepen the reflections on the knowledge of function and of the students, nor on the knowledge of function and teaching processes. Although they were all teachers with classroom experience, little knowledge gained from this experience was considered to compose their responses and discussions.

Group 3. In a different dynamic of groups $G 1$ and G2, the teachers participating in the G3 discussed and negotiated throughout the development of PLT2, both in the first and the second part. We begin our analysis from the transcript of the point at which the PT of G3 discussed item $\boldsymbol{d}$ :

PT5: First, contextualise, right?...

PT7: Could we?... Maybe contextualise more in high school than in elementary school. Maybe. [...] I do not know whether in the elementary level... Because, well, here in the book [Ribeiro and Cury, 2015] there is a lot of contextualised things and he [the book] even says that 'you contextualise according to the degree of... of your students'...

PT5: The age range?

PT7: Yes, age range... Because you have to speak about what he [the student] understands.

PT5: Then: 'taking into account the age range [text that appears in the protocol produced by G3]... [...] there would be a need for contextualisation to generate the interest of the student'... interest and understanding, right? [...] [and the conversation goes on, so that the PT of the G3 obtain the answer presented in the protocol, Figure 6].

We observe that the PT is very concerned with the need to adapt the mathematics situation to the age of students (element of the didactical knowledge concerning the knowledge of their students), and to contextualise the mathematical situations to make them more attractive and motivating to students, emphasising that it must be contextualised for high school students. We can also identify the mobilisation of another element of the didactical knowledge regarding the selection of mathematical tasks that motivate and challenge the students, as well as the care with a language that is accessible and that they can understand easily. However, it seems to us that, on the other hand, the PT does not consider the possibility of contextualizing the situation from the point of view of the mathematics itself, of working with different representations of the concept of function (Figure 6), as happens in all items in the first part of the PLT2.

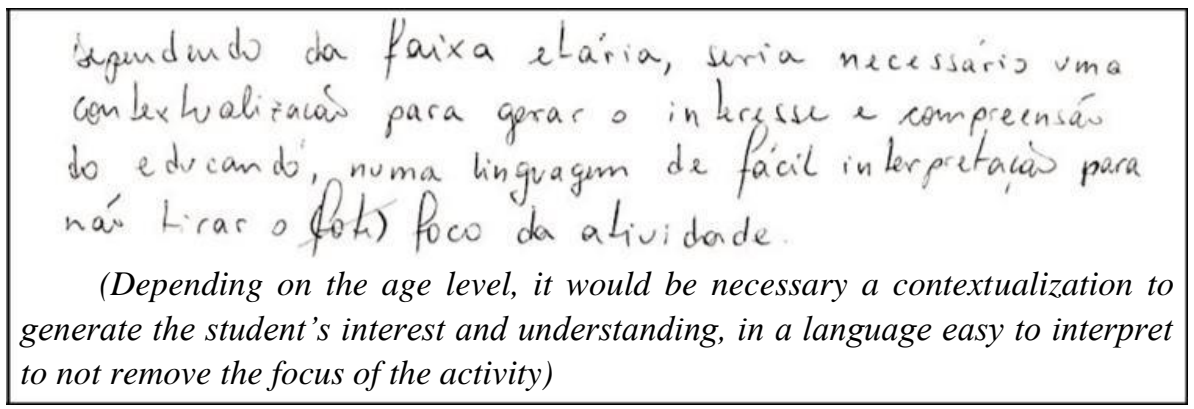

Figure 6. G3 protocol, item $\boldsymbol{d}$, PLT2. 
In items $\boldsymbol{e}$ and $\boldsymbol{f}$, unlike the other two groups, the three PT of G3 emphasise that the difficulties of students could appear, precisely, because it is not customary in the teaching of functions to use the numeric-tabular representation to construct the function rule. According to them, what normally happens is, given the function rule, to seek values for $f(x)$ or $y$, from known values in $x$. In the discussions carried out, we can note that the PT of G3 mobilise elements of didactical knowledge of the functions because they mention that teachers hardly present situations such as those that are considered in the first part of the PLT2.

On the other hand, we did not observe, in discussions that they developed, for example, any reference to the fact of the function considered in item $c$ be as a non-zero term $b(f(x)=a x+b$, with $a$ and $b$ different from 0$)$, whose generalization of the rule (from a table of values) requires a type of mathematical knowledge other than that they mobilise when it comes to affine linear functions $(f(x)=a x$, with $a$ different from 0 ). Also, the PT never became aware that, in that item, they themselves had difficulties in mobilising mathematical knowledge and could not get to the function rule $f(x)=3 x+2$. Finally, after discussing between them, they came to the response shown in Figure 7.

$$
\begin{aligned}
& \text { A dificuldade estaria na formulacáá da lei da funciás } \\
& \text { com os valorex de xey prédefinidas, en uja, fater } 0 \\
& \text { caminho inverso do que normalmewe í proposto }
\end{aligned}
$$

(The difficulty would be in formulating a function rule with the pre-defined values of $x$ and $y$, that is, making the inverse path of what is usually proposed)

Figure 7. G3 protocol, item e, PLT2.

With respect to the use of didactical resources, the PT of G3 begin their discussions around different possibilities to improve the task proposed. However, at the beginning of the conversation, PT7 shows, once again, to be unaware of what is being asked and says:

\section{PT7: Resources?}

Soon after, PT5 already suggests the use of a software (Geogebra) to construct a graph. However, PT5 herself is not sure how to use Geogebra and says:

PT5: So, if you had the software, and inserted it on Geogebra, for example, to make a graph... then you could expand... I mean, before you have the rule, you already have a number there... [...] I don't know!

The brief silence is interrupted by PT6:

PT6: Yeah... also working with entertainment games... instead of working in a simple way.

The discussion seeks to justify how and for what they should use, for example, Geogebra and games, but the PT do not demonstrate, in fact, what the advantages of 
using such resources in performing the task are. Suddenly, PT5 raises the fact that "if we ask students to keep standing, this already draws their (the students) attention, because they are too passive (ill-willing) in the classroom". This demonstrates a certain confusion in the "use of didactical resources in the teaching of mathematics" and "strategies for teaching mathematics". As well as in the G1, we observed that PT of G3 could not tell the difference between "teaching resource" (as in the case of the software Geogebra) and "teaching strategy" (as in the case of working motivation of students in face of the possible difficulties arising from learning in mathematics).

Still, with regard to their not being convinced of how and for what to use such resources in the task, such as Geogebra, PT6 indicates in the statement:

PT6: Geogebra, through Geogebra also... Ah, I'm making a graphic... OK... but... [...] What is the graph for?... right?

This seems to cause some discomfort in the group, but the teachers decide to keep, all the same, the "use of Geogebra".

Along the time, another discussion that could become interesting (but that does not extend) began around the fact that the points mentioned in the table are "discrete":

PT5: And, there is something else too that I thought now, this here [referring to the tables of values] they are discrete points, right?... is not a continuous thing, it is not something like that, that you will be able to connect the dots, here they are... is... You would have to...

PT7: Yes, they are discrete variables.

PT5: It is not simply connecting the dots.

\section{PT7: Continuous.}

There is some confusion with the mathematical language used, referring to points as "discrete points" (and not to the graph of a function involving a discrete variable). The teachers do not notice that the statement of the task already mentions "sets of integer numbers", which implies that the values of $x$ and $y$ could not be used to build a continuous graphical representation, as it would be if we were treating with "sets of real numbers/intervals of real numbers." Although PT5 draws attention to "not being able to connect the dots" and PT7 says that "they are continuous", they do not go deeper into the discussion, whether mathematical or didactical around the usage of functions whose domain and image are discrete sets (as with Z).

Along PLT2, G3 teachers, unlike the other two groups, promoted various discussions and negotiations of knowledge and meanings. In relation to didactical knowledge concerning the concept of function, they pointed out difficulties that students usually have when dealing with the numeric-tabular representation and algebraic notation. Moreover, the PT of G3 also deepened their knowledge on the concept of function from the point of view of teaching, since, along with the completion of PLT2, they identified more appropriate teaching resources and strategies for the work with function in elementary school, such as the use of software and contextualised situations. 


\section{DISCUSSION}

\section{Learning Opportunities about Mathematical Knowledge of Functions}

Regarding the mathematical knowledge about functions, the participant teachers knew how to use tabular and numeric representations and were able to recognize whether they were linear functions with $b$ term zero or non-zero, which can be framed in the common knowledge of the content (Ball et al., 2008) or knowledge based on school algebra (McCrory et al., 2012). In questions involving mathematical knowledge, teachers worked mainly individually, possibly due to their strong familiarity with the issues in question.

However, despite the generality of concepts, we observed that G3 teachers could not establish the rule of a linear function with a non-zero $b$ term in one of the items of PLT2, showing difficulty in differentiating and dealing with algebraic representations proportional and non-proportional functions (Lamon, 2012). We also identified a gap in the mathematical knowledge about functions, with respect to the use of different representations of mathematical concepts, for example with PT7. The verbal representations, in particular, are fundamental to give full meaning to the concept of function, also because many daily life phenomena modelled through functions are presented in a natural language and not in symbolic language. We identified here a PLO when teachers from G3, especially PT7, reorganise their knowledge in relation to be able to distinguish linear function with and without non-zero $b$ term.

In working in PLT2, G3 teachers, including PT7, seem to deal comfortably with a situation involving natural and symbolic language, obtaining the function rule $f(x)=3 x+2$ easily. Here we identify a PLO, since the structure of PLT2 aimed to lead teachers gradually from situations involving natural language to situations that could promote the use of algebraic notation (Cooney et al., 2011).

Although PLT2 was developed by the teacher educators aiming at promoting mathematical discussions of the items proposed, in a general way, it hardly happened. As we noted, the teachers preferred to work mathematics questions individually and, in the end, check with their colleagues the results found and did not go beyond what was asked. Nevertheless, a fact attracted our attention as to how PT12 led the mathematical discussion with his colleagues in the G2. We identify, here, an element of the didactical knowledge pertaining to teaching, since it is expected that the teachers lead mathematical discussions in classrooms, giving voice to the students and leading them to expose their arguments and to discover their possible contradictions (Stein et al., 2008).

\section{Learning Opportunities about Didactic Knowledge of Functions}

Regarding items involving didactic knowledge about functions, unlike what happened with the items concerning mathematical knowledge, the teachers did not feel 
confident in working individually. Possibly, this has to do with the fact that PLT2 involves inquiries on (i) students' difficulties, (ii) teaching resources and approaches, and (iii) the degree of challenge of the tasks for the students. The fact that the answers to these questions are far from consensual motivated the teachers for group work and discussion, essential characteristics of a teacher education process based on practice (Ball \& Cohen, 1999; Stein, 2001).

In relation to the identification of possible difficulties of students when facing mathematical situations such as those proposed in PLT2, we observed a gap in knowledge of teachers about students (Ponte, 2012a). In one of the groups, for example, one of the teachers, PT2, argued that the students would not have difficulties in working with the generalisation and the writing of the function rule from its tabular representation. In contrast, other teachers in this group, as well as in other groups, considered that the students could present difficulties in manipulating the numerical table and in writing the algebraic rule. Here we identify a relevant PLO, as more experienced teachers share their knowledge of students with the novice teacher and convince him that the students experience difficulties in this situation.

Another PLT2 item requested the analysis of the adequacy of the mathematical situation for a certain level of education and student age. At this moment, we could see a PLO, because, the structures of the PLT enabled teachers from different grade levels to work and to discuss in a same group (G2). The participating teachers discussed the need to adjust the mathematical situation to the students' age (element of didactical knowledge concerning knowing students) and the need to contextualise mathematical situations to make them more challenging and motivating to students (element of didactical knowledge concerning teaching processes) (Ponte, 1999).

We also identify here a PLO regarding to the teachers of G3 when they mobilised elements of didactical knowledge regarding functions (Steele et al., 2013), when referring to the lack of habit of teachers and textbooks in presenting situations that depart from numeric tables to formulate a generalisation and an algebraic rule of a function, such as those considered in PLT2. Teachers, in their group discussion around this PLT, reorganised their argumentation about instructional processes (Ponte, 1999) to the teaching of functions.

Still, with regard to didactical knowledge, the use of resources and the choice of teaching approaches are fundamental elements to conduct a class that can foster students' learning. In this sense, PLT2 favoured that, in particular, G3 teachers experienced another learning opportunity to the extent that this provided a reflection on what could be the most appropriate teaching resources and strategies for the concept of function. This was strongly evidenced by PT7's attitude, who showed to be surprised by the fact that the PLT requested that resources that could be used in the mathematical situation presented should be indicated. We perceived, in this situation, a PLO around professional knowledge needed by teachers to select materials for teaching mathematics concepts (Ponte, 1999). It is noteworthy that, from discussing with other group members, PT7 realised what was being requested and what is the meaning, in that context, of the term "resources", and 
the group went on, pointing out Geogebra and the use of games as possible resources for implementing the task about functions.

\section{CONCLUSION}

This article aimss to present and discuss how professional learning tasks (PLT) may provide PLO of mathematics teachers with regard to their mathematical and didactical knowledge of the concept of function. In the research literature that discusses PLO (e.g., Ball \& Cohen, 1999; Bruce et al., 2010; Cochran-Smith \& Lytle, 1999; Lampert, 2010; Loucks-Horsley, 1997; Opfer \& Pedder, 2011; Webster-Wright, 2009), we identified a gap regarding the use of this concept in relation to algebra teaching, in particular regarding the concept of function. We proposed to organise PLT about mathematical and didactical knowledge of functions and investigate their role for teachers to experience such PLO regarding functions and the teaching of this topic.

The results show that the professional learning task (PLT2) proposed in our study enabled teachers to experience professional learning opportunities (PLO) that amplified their mathematical and didactical knowledge of functions. With regard to mathematical knowledge of function, the participants were able to strengthen their capacity to use different forms of representing the concept of function, for example, moving among numeric tables and algebraic notation to verbal representations. Another important dimension of mathematical knowledge of function that was enlarged by teachers refers to the ability to distinguish different kinds of linear functions (with $b$ term zero or non-zero).

Regarding didactical knowledge of function, the PLO provided by the work with PLT2, were based on inquiries on (i) students' difficulties, (ii) teaching resources and approaches, and (iii) the degree of challenge of the tasks for the students. It is interesting that, in contrast with mathematical situations, teachers felt the need to work and discuss within their groups because the questions proposed did not have standard and consensual answers. The teachers had PLO to reorganise their knowledge about the difficulties that the students normally have with the concept of function and with the use of different ways to represent a function, and they could amplify their repertoire about teaching resources and strategies to help students to overcome those difficulties. Finally, we also identified situations where teachers had a PLO to amplify their knowledge around instructional processes and materials to teaching functions in basic education.

The different situations that we presented suggest that the concept of professional learning opportunity (PLO) may be useful in mathematics teacher education. It was possible to organise collective moments of work and discussion among practising teachers around professional learning tasks (PLT) especially designed to mobilise different dimensions of professional knowledge for teaching the concept of function. The structure of PLT and the work in groups allowed teachers to develop their mathematical and didactical knowledge of function in an integrated way, a relevant aspect of knowledge for teaching mathematics at school. 


\section{ACKNOWLEDGEMENTS}

This study was supported by the São Paulo Research Foundation (FAPESP), grant 2016/10622-7. Research data have been collected at Federal University of ABC (UFABC), in Brazil, funded by Capes (Commission for the Improvement of Higher Education Staff) within "Programa Observatório da Educação" (OBEDUC) (Project 1600/2012).

\section{REFERENCES}

Ball, D. L., \& Cohen, D. K. (1999). Developing practice, developing practitioners: Toward a practice-based theory of professional education. In G. Sykes \& L. Darling-Hammond (Eds.), Teaching as the learning profession: Handbook of policy and practice (pp.3-32). San Francisco, CA: Jossey Bass.

Ball, D., Thames, M. H., \& Phelps, G. (2008). Content knowledge for teaching: What makes it special? Journal of Teacher Education, 59(5), 389-407.

Barbosa, Y. O., \& Ribeiro, A. J. (2013). Multisignificados de equação: Uma investigação acerca das concepções de professores de Matemática. Educação Matemática Pesquisa, 15, 379-398.

Bogdan, R., \& Biklen, S. (1994). Investigação qualitativa em educação. Porto: Porto Editora.

Bransford, J. D., Brown, A. L., \& Cocking, R. R. (2000). How people learn: Brain, mind, experience, and school. Washington, D.C.: National Academy Press.

Bruce, C. D., Esmonde, I., Ross, J., Dookie, L., \& Beatty, R. (2010). The effects of sustained classroom-embedded teacher professional learning on teacher efficacy and related student achievement. Teaching and Teacher Education, 26, 1598-1608.

Bush, S. B, \& Karp, K. S. (2013) Prerequisite algebra skills and associated misconceptions of middle grade students: A review. Journal of Mathematical Behavior, 32(3), 613-632. Chazan, D., Yerushalmy, M. \& Leikin, R. (2008) An analytic conception of equation and teachers' views of school algebra. Journal of Mathematical Behavior, 27(2), 87-100.

Cochran-Smith, M., \& Lytle, S. L. (1999). Relationships of knowledge and practice: Teacher learning in communities. Review of Research in Education, 24(1), 249-305. Cooney, T. J., Beckmann, S., \& Lloyd, G. M. (2011). Developing essential understandings of functions for teaching mathematics in grades 9-12. Reston, VA: NCTM.

Cristovão, E. M., \& Fiorentini, D. (2018). Eixos para analisar a aprendizagem profissional docente em comunidades de professores. Unión (San Cristobal De La Laguna), v. 52, p.11-33.

Crotty, M. (1998). The foundations of social research: Meaning and perspective in the research process. London: Sage.

Cyrino, M., \& Oliveira, H. (2011). Pensamento algébrico ao longo do ensino básico em Portugal. Bolema, 24(38), 97-126.

Doerr, H. M. (2004). Teachers' knowledge and teaching of algebra. In K Stacey, H. Chick, \& M. Kendal (Ed.). The future of the teaching and learning of algebra: The 12 th ICMI Study (pp.267-289). Boston, MA: Kluwer, 
Esteban, M. P. S. (2010). Pesquisa qualitativa em educação: Fundamentos e tradições.

Porto Alegre: Artmed.

Even, R. (1993). Subject-matter knowledge and pedagogical content knowledge: Prospective secondary teachers and the function concept. Journal for Research in Mathematics Education, 24(2), 94-116.

Grossman, P., Compton, C., Igra, D., Ronfeldt, M., Shahan, E., \& Williamson, P. (2009). Teaching practice: A cross-professional perspective. Teachers College Record, 111(9), 2055-2100.

Kaput, J. (2008). What is algebra? What is algebraic reasoning? In J. J. Kaput, D. W. Carraher \& M. L. Blanton (Eds.), Algebra in the early grades (pp.5-17). New York, NY: Routledge.

Lamon, S. J. (2012). Teaching fractions and ratios for understanding: Essential content knowledge and instructional strategies for teachers $\left(2_{\mathrm{nd}} \mathrm{ed}.\right)$. New York, NY: Routledge.

Lampert, M. (2010). Learning teaching in, from, and for practice: What do we mean? Journal of Teacher Education, 61(1-2) 21-34.

Lampert, M., \& Ball, D. L. (1998). Teaching, multimedia, and mathematics. New York:

Teachers College Press.

Lesh, R., Post, T., \& Behr, M. (1987) . Representations and translation among representations in mathematics learning and problem solving. In C. Janvier (Ed.), Problems of representation in the teaching and learning of mathematics (pp.33-40). Hillsdale, NJ: Erlbaum.

Lesne, M. (1984). Trabalho pedagógico e formação de adultos. Lisboa: Fundação Calouste Gulbenkian.

Li, X. (2007). An investigation of secondary school Algebra teachers' mathematical knowledge for teaching algebraic equation solving. ( $\mathrm{PhD}$ Thesis at The University of Texas at Austin, Austin, USA).

Llinares, S. (2000). Secondary school mathematics teacher's professional knowledge: A case from the teaching of the concept of function, Teachers and Teaching: theory and practice, 6(1), 41-62.

Loucks-Horsley, S. (1997). Teacher change, staff development, and systemic change: Reflections from the eye of the paradigm. In S. N. Friel \& G.W. Bright (Eds.), Reflecting on our work: NSF teacher enhancement in K-6 mathematics (pp.133-150). Lanham, MD: University Press of America.

Loucks-Horsley, S., Hewson, P. W., Love, N., \& Stiles, K. E. (1998). Designing professional development for teachers of science and mathematics. Thousand Oaks: Corwin Press.

Matos, A. S., \& Ponte, J. P. (2009). Exploring functional relationships to foster algebraic thinking in grade 8. Quaderni di Ricerca in Didattica (Matematica), Itália, Supplemento n.2 al n.19.

McCrory, R., Floden, R., Ferrini-Mundy, J., Reckase, M. D., \& Senk, S. L. (2012). Knowledge of algebra for teaching: A framework of knowledge and practices. Journal for Research in Mathematics Education, 43(5), 584-615. 
Opfer, V. D., \& Pedder, D. (2011). Conceptualizing teacher professional learning. Review of Educational Research, 81(3), 376-407.

Panoura, A., Michael-Chrysanthou, P., Gagatsis, A., Elia, I., \& Philippou, A. (2017). A structural model related to the understanding of the concept of function: Definition and problem solving. International Journal of Science and Mathematics Education, 15, 723-740. DOI 10.1007/s10763-016-9714-1.

Pazuch, V., \& Ribeiro, A. J. (2017). Conhecimento profissional de professores de matemática e o conceito de função: uma revisão de literatura. Educação Matemática Pesquisa, São Paulo, 19, 465-496.

Ponte, J. P. (1994). Mathematics teachers' professional knowledge. In J. P. Ponte \& J. F. Matos (Eds.). Proceedings of the 18 th Conference of the International Group for the Psychology of Mathematics Education (v. 1, pp.195-210). Lisboa, Portugal: PME.

Ponte, J. P. (1999). Didácticas específicas e construção do conhecimento profissional. In J. Tavares (Eds.). Investigar e formar em educação: Actas do IV congresso da SPCE (pp.59-72), Porto: SPCE.

Ponte, J. P. (2012a). Estudiando el conocimiento y el desarrollo profesional del profesorado de matemáticas. In N. Planas (Ed.), Teoría, crítica y prática de la educación matemática (pp.83-98). Barcelona: Graó.

Ponte, J. P. (2012b). A practice-oriented professional development programme to support the introduction of a new mathematics curriculum in Portugal. Journal of Mathematics Teacher Education, 15(4), 317-327.

Ponte, J. P. (2017). Discussões coletivas no ensino-aprendizagem em Matemática. In GTI (Ed.), A prática dos professores: planificação e discussão coletiva na sala de aula (pp.33-56). Lisboa: APM.

Ponte, J. P., \& Chapman, O. (2008). Preservice mathematics teachers' knowledge and development. In: English, L. D. (Ed.). Handbook of International Research in Mathematics Education (2nd ed. pp.225-263). New York, NY: Routledge.

Remillard, J. T., \& Geist, K. (2002). Supporting teachers' professional learning by navigating openings in the curriculum. Journal of Mathematics Teacher Education, 5, 7-34. Ribeiro, A. J. (2012). Equação e Conhecimento Matemático para o Ensino: relações e potencialidades para a Educação Matemática. Bolema, 26(42), 535-557.

Ribeiro, A. J., \& Cury, H. N. (2015). Álgebra para a formação do professor: explorando os conceitos de equação e de função. Belo Horizonte: Autêntica.

Shulman, L. S. (1986). Those who understand: knowledge growth in teaching. Educational Researcher, 15(2), 4-14.

Silver, E. A., Clark, L. M., Ghousseini, H. N., Charalambous, C. Y., \& Sealy, J. T. (2007). Where is the mathematics? Examining teachers' mathematical learning opportunities in practice-based professional learning tasks. Journal of Mathematics Teacher Education, 10, 261-277.

Smith, M. S. (2001). Practice-based professional development for teachers of mathematics.

Reston, VA: NCTM.

Steele, M. D., Hillen, A. F., \& Smith, M. S. (2013). Developing mathematical knowledge for teaching in a methods course: the case of function. Journal of Mathematics Teacher Education, 16, 451-482. 
Stein, M. K., Engle, R. A., Smith, M. S., \& Hughes, E. K. (2008) Orchestrating productive mathematical discussions: Five practices for helping teachers move beyond show and tell. Mathematical Thinking and Learning, 10, 313-340.

Stephens, M., \& Ribeiro, A. J. (2012). Working towards algebra: The importance of relational thinking. RELIME, 15, 307-401.

Swan, M. (2007). The impact of task based professional development on teachers' practices and beliefs: A design research study. Journal of Mathematics Teacher Education, 10, 217-237.

Wasserman, N. H. (2015). Unpacking teachers' moves in the classroom: navigating micro-and macro-levels of mathematical complexity. Educational Studies in Mathematics, Rotterdam, n.90, p.75-93.

Webber, E., Tallman, M. A., \& Middleton, J. A. (2015). Developing elementary teachers' knowledge about functions and rate of change through modeling, Mathematical Thinking and Learning, 17(1), 1-33, DOI: 10.1080/10986065.2015.981940.

Webster-Wright, A. (2009). Reframing professional development through understanding authentic professional learning. Review of Educational Research, 79(2), 702-739. White, A. L., Jaworski, B., Agudelo-Valderrama, C., \& Gooya, Z. (2013). Teachers learning from teachers. In M. A. (Ken) Clements et al. (Eds.), Third International Handbook of Mathematics Education (pp.393-430). New York, NY: Springer.

\section{Appendix I}

\section{Professional Learning Task 2 (PLT2): "Studying functions from a mathematical and didactical point of view"}

Based on questions proposed by Ribeiro and Cury (2015) The following tables show sets of integers. In each case, answer the questions:

a)

\begin{tabular}{|l|l|}
\hline $\mathbf{X}$ & $\mathbf{Y}$ \\
\hline 1 & 6 \\
2 & 6 \\
3 & 7 \\
4 & 8 \\
5 & 9 \\
6 & 10 \\
7 & $\ldots$ \\
8 & 12 \\
$\ldots$ & $\ldots$ \\
\hline
\end{tabular}


1) When $x$ is 2, what is the value of $y$ ?

2) When $x$ is 6, what is the value of $y$ ?

3) When $x$ is 8 , what is the value of $y$ ?

4) When $x$ is 800, what is the value of $y$ ?

5) Write, with your words, the rule that takes each $x$ to the corresponding $y$.

6) Write this rule now, using only letters and numbers.

b)

\begin{tabular}{|l|l|}
\hline $\mathbf{P}$ & $\mathbf{Q}$ \\
\hline 2 & 6 \\
3 & 9 \\
4 & 12 \\
5 & 15 \\
$\ldots$ & $\ldots$ \\
\hline
\end{tabular}

1) when $P$ is 2, what is the value of $Q$ ?

2) when $P$ is 5, what is the value of $Q$ ?

3) write a rule that represents this situation, using only letters and numbers.

c)

\begin{tabular}{|l|l|}
\hline$x$ & $y$ \\
\hline 0 & 2 \\
1 & 5 \\
2 & 8 \\
3 & 11 \\
4 & 14 \\
5 & 17 \\
6 & $\ldots$ \\
$\ldots$ & $\ldots$ \\
\hline
\end{tabular}

1) when $x=2$, what is the value of $y$ ?

2) when $x=6$, what is the value of $y$ ?

3) write a rule that represents this situation and then calculate the value of $y$ when $x=12$. 
d) Looking at this task, discuss whether it could be used in elementary, middle and high school. What adaptations would you make in this task to work at both levels of education (elementary, middle and high school)? Justify your answers.

e) What difficulties could students present in solving this task?

f) Which didactic resources (digital or not) could improve this task? Describe how you would do this. 